\title{
Fluorosurfactants in Enhanced Oil Recovery
}

\author{
Peter M. Murphy ${ }^{*}$ and Tracy Hewat
}

DuPont Experimental Station, 200 Powder Mill Road, ESL402/5337, Wilmington, DE 19803, USA

\begin{abstract}
Fluorosurfactants are effective in a variety of Enhanced Oil Recovery (EOR) techniques including (i) improving subterranean wetting, (ii) increasing foam stability, and (iii) modifying the surface properties of the reservoir formation. While fluorosurfactants have been used in gas and oil exploration for four decades, the increased demand for petroleum and the greater understanding of the benefits of fluorosurfactants have led to growing acceptance for fluorosurfactants throughout the petroleum industry. This mini-review summarizes the published research for fluorosurfactants in EOR from 1977 to 2007 . The references in this mini-review are mostly patents ( $v s$ peer reviewed articles) and laboratory models of the benefits of fluorosurfactants in EOR ( $v s$ actual oil and gas recovery experiments). This summary of the published reports on fluorosurfactants in EOR provides petroleum scientists and engineers an overview of this emerging technology.
\end{abstract}

Keywords: Fluorosurfactant, enhanced oil recovery, foam, wetting, petroleum.

\section{INTRODUCTION}

Petroleum is the most critical energy source in the world, especially for transportation. In 2008, the U.S. Department of Energy projected worldwide consumption of "liquids and other petroleum grows from 83.6 million barrels oil equivalent per day in 2005 to 95.7 million barrels per day in 2015 $(+14 \%)$ and 112.5 million barrels per day in $2030(+35 \%)$ " [1]. While estimates vary, the peaking of worldwide conventional oil production is a serious concern that has perhaps already taken place or will occur within the next few decades [2]. The pressures of increasing oil demand, limited proven oil reserves, and forecasts for tightening oil supply are driving the need to maximize the extraction of the Original OilIn-Place (OOIP) for every reservoir, which is accelerating the development of Enhanced Oil Recovery (EOR) technologies. The presence of many interfaces and the complexity of the physico-chemical and geological characteristics of the reservoirs make EOR an immense scientific and technical challenge [3].

The production of crude oil and gas occurs in three distinct phases [4]. Primary Oil Recovery combines the natural pressure of the reservoir with pumping equipment to bring the oil to the surface, which typically produces only up to about $10 \%$ of the OOIP. In Secondary Oil Recovery, water or gas (such as natural gas, carbon dioxide, and air) is injected into the reservoir using pressure to drive the oil to a wellbore, recovering an additional $20 \%$ to $40 \%$ of the OOIP. Tertiary Oil Recovery (also known as EOR or Improved Oil Recovery) uses one or more sophisticated techniques including chemical flooding, thermal recovery, and gas injection to recover up to an additional $60 \%$ of the OOIP. Thermal techniques normally employ steam to reduce the viscosity of the oil, thus improving its flow. Chemicals used in EOR include

*Address correspondence to this author at the DuPont Experimental Station, 200 Powder Mill Road, ESL402/5337, Wilmington, DE 19803, USA; Tel: 302-695-6675; Fax: 302-695-8680;

E-mail: peter.m.murphy@usa.dupont.com polymers, surfactants, foaming agents, acids, alkalines, and solvents [5]. The gases successfully used in EOR include nitrogen, carbon dioxide, natural gas, and flue gas. Many fluid/rock interactions affect EOR including adsorption, cation exchange, precipitation-dissolution, capillary phenomena, wetting, and dispersion [6].

Surfactants are widely used in oil recovery for particle dispersion, emulsion stabilization, foam generation, reservoir wetting, and many other applications [7]. The use of fluorosurfactants is a recent but growing trend due to (i) the exceptional hydrophobic and oleophobic nature of the perfluoroalkyl and perfluoroalkyl ether groups, (ii) the effectiveness of fluorosurfactants at extremely low concentrations, and (iii) the availability of anionic, cationic, nonionic, and amphoteric fluorosurfactants which can modify surfaces and interfaces better than conventional hydrocarbon surfactants [8]. The variety of choices of fluorosurfactants allows for compatibility with nearly any formulation including water-in-oil emulsions, oil-in-water emulsion, detergents, foams, etc. The bond strength of the carbon-fluorine bond in perfluoroalkyl and perfluoroalkyl ether groups has been demonstrated as the key to remarkable overall stability for fluorochemicals and fluoropolymers. Commercially available fluorosurfactants provide exceptional wetting, levelling, emulsifying, foaming, or repellency characteristics in a wide range of industrial and consumer products [9].

\section{IMPROVED SUBTERRANEAN WETTING}

Fluorosurfactants possess a combination of excellent chemical and thermal stability, and wetting ability. Table 1 shows these characteristics of fluorosurfactants with their exceptionally low aqueous surface tension (even lower than alcohol-water mixtures) being unaffected by 20 hours at $100^{\circ} \mathrm{C}$ in either $\mathrm{KCl}$ or $\mathrm{HCl}$ [10]. Complete drainage of aqueous $\mathrm{KCl}$ containing fluorosurfactants through sandpacks or sandstone was attributed to these low surface tension values overcoming the capillary forces commonly seen in underground oil and gas reservoirs. The choice of the hydrophilic portion of a fluorosurfactant was critical to minimize 
its adsorption to the formation and loss of wetting effectiveness. Anionic and nonionic fluorosurfactants demonstrated significantly less adsorption to Oklahoma No. 1 sand than cationic or amphoteric fluorosurfactants. The adsorption of any particular fluorosurfactant to a solid matrix varied considerably depending on temperature, liquid phase composition, and the chemistry of the simulated formation. Concerns about capillary blockage due to adsorption of the fluorosurfactant to the formation were examined using coreflow studies with low-permeability sandstone cores. At $75^{\circ} \mathrm{C}$ and 6850 $\mathrm{kPa}$ of nitrogen, essentially no difference was observed in initial flow rate with or without a cationic fluorosurfactant in $2 \mathrm{wt} \% \mathrm{KCl}$.

Nonionic fluorosurfactants enhanced the oil recovery of waterflooding due to their benefits of enhanced wetting, low surface tension, and low interfacial tension. Using a mixture of $10 \%$ ASTM oil No. 3 and $90 \%$ Ottawa standard 20-30 mesh sand to simulate waterflooding in the laboratory, hydrocarbon surfactants gave between $8 \%$ and $52 \%$ oil recovery, while nonionic fluorosurfactants gave between $10 \%$ and $87 \%$ oil recovery. Blends of hydrocarbon surfactants and nonionic fluorosurfactants gave between $12 \%$ and $78 \%$ oil recovery [11].

Cationic fluorosurfactants, when combined with cationic and nonionic hydrocarbon surfactants in water, brine, or various concentrations of aqueous $\mathrm{HCl}$ provided improved foaming, better silt suspension, and enhanced wetting for treating subterranean formations, important predictors of the effectiveness of acidizing treatments [12]. A blend of hydrocarbon surfactants containing only about $10 \mathrm{ppm}$ of cationic fluorosurfactant lowered the surface tension of aqueous $\mathrm{HCl}$ (ranging from 3 to 28 weight percent $\mathrm{HCl}$ in both fresh acid and simulated spent acid containing calcium carbonate) to between 18 to $24 \mathrm{mN} / \mathrm{m}$.

Acid fracturing is a well stimulation technique that injects aqueous $\mathrm{HCl}$ or $\mathrm{HF}$ (typically 3 weight percent to 28 weight percent acid) into the well at high pressures causing the porous media to fracture and release gas and oil for recovery. Surfactants are mixed with these acids to increase their wetting of the hydrophobic carbonate surfaces in the reservoir. When less than $30 \mathrm{ppm}$ of cationic fluorosurfactants were added to mixtures of aqueous acid and hydrocarbon surfactant, the surface tension of these aqueous acids dropped to between about 19 and $24 \mathrm{mN} / \mathrm{m} \mathrm{[13].} \mathrm{Similar} \mathrm{reductions} \mathrm{in} \mathrm{surface} \mathrm{tension} \mathrm{and}$ improved wetting were observed when fluorosurfactants were added to brine solutions used for non-acid fracturing. A formulation containing hydrocarbon surfactants and a cationic fluorosurfactant reduced the surface tension of a solution of 8 weight percent sodium chloride and 2.5 weight percent calcium chloride to $22.8 \mathrm{mN} / \mathrm{m}$ compared to $74.3 \mathrm{mN} / \mathrm{m}$ without the addition of the fluorosurfactant and hydrocarbon surfactants.

For Thermal EOR, the choice of surfactant and $\mathrm{pH}$ control were found to be critical to achieve the desired low surface tension in the steam condensate necessary for effective recovery of the OOIP [14]. Unless sufficient fluorosurfactant condensed in the steam/gas phase, the reduction of surface tension would be insufficient. Hydrocarbon surfactants or inappropriate $\mathrm{pH}$ control for fluorosurfactants gave steam condensate with relatively high surface tension values of between 47 and $51 \mathrm{mN} / \mathrm{m}$. But with $\mathrm{pH}$ less than about 11 in the liquid phase, nonionic or anionic fluorosurfactants were able to accumulate in the steam/gas phase and to lower the surface tension values in the steam condensate to between 22 and $25 \mathrm{mN} / \mathrm{m}$.

In non-aqueous systems, fluorosurfactants have improved the wetting and emulsion stability of hydrocarbons in liquefied $\mathrm{CO}_{2}$ formulations for fracturing fluids [15]. Both labstock diesel and Frac Oil $200^{\mathrm{TM}}$ were successfully emulsified in liquid $\mathrm{CO}_{2}$ with hydrofluoroether surfactants to produce a fracturing fluid with increasing stability when subject to shear. Fluorosurfactants also improved emulsion stability in multiphase systems of perfluoroethers used for drilling, completion, or workover fluids [16]. High fluid density and thermal stability are the essential properties of liquid fluorinated compounds which make them suitable as the continuous phase of well fluids. Fluorosurfactants stabilized the brine-in-perfluoroether emulsion which can contain other organic materials, minerals, clays, and inorganic salts. Examples of stable formulations ranging from $88 \%$ to $13 \%$ fluorinated liquid by volume, with the remainder barite, calcium carbonate, or saturated calcium chloride brine were demonstrated.

\section{INCREASED FOAM STABILITY}

For foam injection EOR, fluorosurfactants have the unique benefit to generate foam that is stable in contact with the crude oil, while imbibing and transporting the oil through the subterranean formation. Three types of oil-foam interactions are contrasted [17]. In Type A foams, oil will neither spread over nor enter the surface of foam. In Type B foams, oil will enter but not spread over the surface of foam. In Type $\mathrm{C}$ foams, oil will enter the surface of foam lamellae, then spread over the lamellae surfaces and destabilize the foam. Type B foams resulted in increased oil recovery by reducing and controlling the mobility of the foam in the underground formation. While brine alone (waterflooding) recovered $56 \%$ of the OOIP from a Berea sandstone saturated with crude oil, the Type B foam containing hydrocarbon and fluorinated surfactants recovered $68 \%$ of the OOIP. The higher oil recovery for Type B foams was attributed to the "oil-imbibing and transporting properties of Type B foams".

Table 1. Surface Tension and Stability of Fluorosurfactants in Aqueous KCl or HCl

\begin{tabular}{|c|c|c|c|c|c|}
\hline $\begin{array}{c}\text { Surface } \\
\text { Tension }(\mathbf{m N} / \mathbf{m})\end{array}$ & $\begin{array}{c}\text { No } \\
\text { Fluorosurfactant }\end{array}$ & $\begin{array}{c}\text { Cationic } \\
\text { Fluorosurfactant }\end{array}$ & $\begin{array}{c}\text { Nonionic } \\
\text { Fluorosurfactant }\end{array}$ & $\begin{array}{c}\text { Anionic } \\
\text { Fluorosurfactant }\end{array}$ & $\begin{array}{c}\text { Amphoteric } \\
\text { Fluorosurfactant }\end{array}$ \\
\hline \hline $2 \mathrm{wt} \%$ aqueous $\mathrm{KCl}$ & 73 & 18 & 21 & 17 & 18 \\
\hline $2 \mathrm{wt} \%$ aqueous $\mathrm{KCl}$ after 20 hours at $100^{\circ} \mathrm{C}$ & - & 19 & 24 & 18 & 19 \\
\hline $15 \mathrm{wt} \%$ aqueous $\mathrm{HCl}$ & 71 & 18 & 21 & 16 & 16 \\
\hline $15 \mathrm{wt} \%$ aqueous $\mathrm{HCl}$ after 20 hours at $100^{\circ} \mathrm{C}$ & - & 17 & 23 & 21 \\
\hline
\end{tabular}


Betaine fluorosurfactant generated very stable foam in the presence of different alkanes or crude oils. Detailed analyses of the foam characteristics of either (i) an amphoteric fluorosurfactant or (ii) a C14-C16 sulfonate (AOS) formulation showed that only the fluorosurfactant had negative spreading coefficients for all crude oils tested, which explained the consistent stability of these foams in the presence of the oils [18]. For the betaine fluorosurfactant the Lamella number was less than one for a series of hydrocarbons from $\mathrm{C}_{5}$ through $\mathrm{C}_{16}$, indicating a Type $\mathrm{A}$ foam. The corresponding Lamella number and spreading coefficient for the AOS surfactant was between one and seven, and greater than zero, respectively. The betaine fluorosurfactant also gave consistently more dense foam in the presence of crude oil than the AOS foam. While both surfactants gave stable foam with the addition of methanol, only the betaine fluorosurfactant gave stable foam with low to moderate concentrations of butanol.

The addition of betaine fluorosurfactants to anionic or amphoteric hydrocarbon foaming agents improved aqueous foam stability in the presence of crude oil by up to nearly $300 \%$ at low crude oil concentrations [19]. At higher crude oil concentrations, the hydrocarbon foaming agents failed to sustain any stable foam, while the addition of fluorosurfactants continued to provide a robust foam. Coreflood foam modelling using Berea sandstone flooded with crude oil and brine showed the benefits for the blends of fluorosurfactant and hydrocarbon foaming agent in EOR. When tested at the residual oil saturation point ( $28 \%$ of pore volume), hydrocarbon foaming agents gave Mobility Reduction Factor (MRF is the ratio of pressure drops with $v s$ without surfactant) of about 2 to 3 , while blends of fluorosurfactant and hydrocarbon foaming agent increased the MRF to between 10 and 40.

Cationic, amphoteric, and betaine fluorosurfactants dramatically improved the recovery of OOIP from silica (500 micron diameter glass balls) compared to either nitrogen gas purging alone or sodium benzene sulfonate (SBS) foaming [20] (Table 2). Photographic evidence showed that the oil bank was pushed through the silica packed cell by a stable fluorosurfactant foam front, perpendicular to the axis of the porous medium. Bi-strata porous media formed from two layers of glass balls with different diameters also showed a fluorosurfactant foam front moving simultaneously through both zones, first sweeping the oil from the more permeable zone, then clearing the oil from the less permeable layer.

Table 2. Simulated Oil Recovery from Silica

\begin{tabular}{|c|c|c|}
\hline Purge & $\begin{array}{c}\text { Gas Volume (Multiples } \\
\text { of Pore Volume) }\end{array}$ & $\begin{array}{c}\text { OOIP } \\
\text { Recovery }\end{array}$ \\
\hline \hline Nitrogen only & 100 & $50 \%$ \\
\hline $\begin{array}{c}\text { Sodium benzene } \\
\text { sulfonate foam }\end{array}$ & 100 & $100 \%$ \\
\hline $\begin{array}{c}\text { Cationic } \\
\text { fluorosurfactant foam }\end{array}$ & 1 & $100 \%$ \\
\hline
\end{tabular}

\section{MODIFYING THE SURFACE PROPERTIES OF THE RESERVOIR}

Water blocking occurs in gas or oil wells when water, mud, brine, or crude oil accumulates near the wellbore, resulting in reduced permeability to oil and gas, and thus reduced recovery. Water blocking was reduced when sandstone was treated with a variety of fluorosurfactants to simulate modifying the wetting characteristics of an underground gas and oil reservoir formation. Core testing on sandstone treated with fluorosurfactants showed greater brine removal and lower pressure drop across the structure due to reduced capillary pressure in the small pores, which was attributed to altered wettability of the fluorosurfactant-treated sandstone [21]. With polymeric fluorosurfactants, the sandstone was rendered durably repellent to water, which offered the best remedy to alleviate water blocking by transforming the formation from water-wet or oil-wet to intermediate-wet or gaswet. Water contact angles on the untreated sandstone were essentially zero. After treatment with fluorosurfactants, the contact angles on the treated sandstone were greater than $90^{\circ}$. Water imbibition test on dry untreated sandstone compared to dry fluorosurfactant treated sandstone showed both (i) a reduction in the rate of water uptake (saturation at 1 hour for untreated sandstone $v s$ more than 12 hours for fluorosurfactant treated sandstone) and (ii) a decrease in percent water imbibed at equilibrium (about $45 \%$ to $55 \%$ for untreated sandstone $v s \quad 15 \%$ to $30 \%$ for fluorosurfactant treated sandstone).

Cationic polymeric fluorosurfactants in methanol were used to treat sand and "... resist or substantially reduce the wetting of the surfaces by water and hydrocarbons and provided high interfacial tensions between the surfaces and water and hydrocarbons ... and significantly increases the flow of hydrocarbons through capillaries or flow channels in the formations [22]." Laboratory tests showed that oil flowed through the fluorosurfactant-treated sand at a rate between 60 and 150 times faster than untreated sand. This EOR technique using fluorosurfactants was employed at a well in Moffat County, Colorado from the Fort Union Sand Formation using methanol, 0.2 weight percent $\mathrm{C}_{10-12}$ alcohol ethoxylates, and 0.01 weight percent of a cationic polymeric fluorosurfactant. After treatment, the gas productivity increased from 100 million cubic feet (MCF) per day to 300 MCF per day.

When used in combination with methanol hydraulic fracturing, various nonionic polymeric fluorosurfactants improved the gas permeability of methane, butane, and higher alkane blends for Berea sandstone by between $13 \%$ and $282 \%$ [23]. The benefits of the nonionic polymeric fluorosurfactants in this EOR technique could include better capillary wetting, inhibiting water blocking, delaying condensate bank formation, or modifying the wetting characteristics of the sandstone. Polymeric fluorosilane surfactants were used to durably alter the surface properties of three wettability states of Berea sandstone (water-wet, weakly water-wet, weakly oil-wet) to intermediate gas-wetting [24]. Gas recovery by oil injection for the untreated Berea sandstone was $60 \%$ at oil breakthrough compared to $80 \%$ for the polymeric

fluorosilane treated sample. Total gas recovery for the untreated Berea sandstone was $80 \%$ compared to $90 \%$ for the polymeric fluorosilane treated sample. Total oil recovery 
with simulated water injection for the untreated Berea sandstone was $54 \%$ compared to $76 \%$ for the polymeric fluorosilane treated sample.

Laboratory studies showed that fluorosilane surfactants also provided durable changes in the wetting characteristics of calcite, marble, mica, and silica. As the chain length of the perfluoroalkyl portion of the fluorosilane surfactant increased, the rocks became less water-wet and more repellent. Brine contact angles on calcite and mica increased from about $33^{\circ}$ and about $17^{\circ}$, respectively, for the untreated surfaces to between $64^{\circ}$ and $118^{\circ}$ for either mineral surface treated with fluorosilane surfactants [25]. Significantly altered wetting can only occur if the contact angle is greater than $90^{\circ}$. For carbonate cores treated with fluorosurfactants, the residual brine saturation was reduced by $25 \%$ and the gas relative permeability increased almost 160 times. These high contact angles and increased gas permeabilities are attributed to the success of fluorosurfactants in lowering the surface energy of the mineral surfaces. By reducing the water wettability of the formation, the capillaries are less blocked, pressure drops are reduced, and gas recovery is more effective.

\section{CONCLUSION}

The published patents and papers describing the use of fluorosurfactants in Enhanced Oil Recovery (EOR) show the exceptional benefits for this technology in (i) improving subterranean wetting, (ii) increasing foam stability, and (iii) modifying the surface properties of the reservoir. Technical advances and economic trends point toward the increasing use of fluorosurfactants in EOR. Future research in this field should include (a) the benefits of fluorosurfactants in EOR from more actual oil/gas formation recovery, (b) the details of fluorosurfactant recycling and recovery in EOR, (c) the impact of fluorosurfactants in EOR on the entire oil/gas recovery and refinery processes, and (d) the economics and environmental benefits of fluorosurfactants in EOR.

\section{REFERENCES}

[1] "International Energy Outlook 2008", U.S. Department of Energy Report EIA-0484. [Online] Available http://www.eia.doe.gov/oiaf/ ieo/index.html [Accessed August 28, 2008].

[2] D. L. Greene, J. L. Hopson, and J. Li, "Have we run out of oil yet? Oil peaking analysis from an optimist's perspective", Energy Policy, vol. 34, pp. 515-531, March 2006.

[3] J. Kanicky, J. Lopez-Montilla, S. Pandey, and D. Shah, "Surface Chemistry in the Petroleum Industry", in Handbook of applied surface and colloid chemistry, John Wiley \& Sons, 2002, pp. 251-267.

[4] U.S. Department of Energy website [Online] Available http://www. fossil.energy.gov/programs/oilgas/eor/index.html [Accessed February 08,2008$]$.

[5] L. L. Schramm, Foams: Fundamentals and Applications in the Petroleum Industry, Cambridge University Press, Cambridge, 1994, pp. 355-399.
[6] L. L. Schramm, Surfactants: Fundamentals and Applications in the Petroleum Industry, Cambridge University Press, Cambridge, 2000, pp. 121-155 and 297-399. G. A. Pope, "Reduction of capillary forces by surfactants", Crit. Rep. Appl. Chem., vol. 33, pp. 89$122,1991$.

[7] L. L. Schramm, Surfactants: Fundamentals and Applications in the Petroleum Industry, Cambridge University Press, 2000, pp. 297399. A. Bhardwaj, and S. Hartland, "Applications of surfactants in petroleum industry", Dispers. Sci. Technol., vol. 14(1), pp. 87-116, February 1993

[8] E. Kissa, Fluorinated Surfactants: Synthesis, Properties and Applications, Marcel Dekker, Inc, vol. 50, 1994.

[9] See for example, M. Haniff, T. Deisenroth, J. Jennings, and K. F. Mueller, "Perfluoroalkyl-substituted amines, acids, amino acids and thioether acids", U.S. Patent 6,706,923, March 16, 2004; and P. M. Savu, and S. A. Etienne, "Fluorochemical sulfonamide surfactants", U.S. Patent 6,664,354, December 16, 2003.

[10] H. Clark, M. Pike, and G. Rengel, "Water-soluble fluorochemical surfactant well simulation additives", J. Petrol. Technol., vol. 34(7), pp. 1565-1569, July 1982.

[11] T. W. Cooke, "Oil recovery for fluorochemical surfactant waterflooding", U. K. patent 2,031,482, June 6, 1979.

[12] J. L. Thompson, "Foaming and silt suspending agent", U.S. Patent 4,108,782, August 22, 1978 .

[13] J. L. Thompson, "Composition and method for reducing the surface tension of aqueous fluids", U.S. Patent 4,018,689, April 19, 1977.

[14] D. R. Watkins, "Compositions for use in steam enhanced oil recovery processes", U.S. Patent 4,975,208, December 4, 1990.

[15] D. V. S. Gupta, "Liquid $\mathrm{CO}_{2}$ /hydrocarbon oil emulsion fracturing system", U.S. patent 6,509,300, January 21, 2003.

[16] D. Pasquier, A. Draincourt, and A. Audibert, "Well fluid comprising a fluorinated liquid phase", U.S. patent application 2007/0123430, May 31, 2007.

[17] L. L. Schramm, C. Ayasse, K. Mannhardt, and J. Novosad, "Method for improving enhanced recovery of oil using surfactantstabilized foams", U.S. Patent 5,060,727, October 29, 1991.

[18] A. Vikingstad, M. Aarra, and A. Skauge, "Effect of surfactant structure on foam-oil interactions. Comparing fluorinated surfactant and alpha olefin sulfonate in static foam tests", Colloids and Surfaces A: Physiochem. Eng. Aspects, vol. 279, pp. 105-112, May 2006.

[19] W. A. Rendall, C. Ayasse, and J. Novosad, "Surfactant-stabilized foams for enhanced oil recovery", U.S. Patent 5,074,358, (December 24, 1991).

[20] M. Robin and C. Demay, "Process for improving the gas sweeping of an oil formation, using foams mainly containing surfactants with perfluoric groups", U.S. Patent 4,836,281, June 6, 1989 .

[21] M. K. R. Panga, M. Samuel, K. S. Chan, P. Enkababian, and P. Cheneviere, "Prevention of Water and Condensate Blocks in Wells", U.S. Patent Application 2007/0029085, February 8, 2007.

[22] A. Pope, M. Sharma, V. Kumar, and J. Baran, "Use of Fluorocarbon Surfactants to Improve the Productivity of Gas and Gas Condensate Wells", U.S. Patent Application 2007/0225176, September 27, 2007.

[23] G. S. Penny, and J. E. Briscoe, "Method of increasing hydrocarbon production by remedial well treatment", U.S. Patent 4,565,639, January $21,1986$.

[24] G. Tang, and A. Firoozabadi, "Wettability alteration to intermediate gas-wetting in porous media at elevated temperatures", Transp. Porous Media, vol. 52(2), pp. 185-211, August 2003.

[25] B. Adabhatla, K. Mohanty, P. Berger, and C. Lee, "Effect of surfactants on wettability of near-wellborne regions of gas reservoirs", J. Petrol. Sci. Eng., vol. 52, pp. 227-236, June 2006. 